\title{
Dyke-Davidoff-Masson syndrome: A case report from South India
}

\author{
Sowjan $\mathbf{M}^{1}$, Vikram R ${ }^{2}$, Rajakumar P.G ${ }^{3}$, Mohammad $\mathrm{Ali}^{4}$ \\ ${ }^{1}$ Dr. Sowjan M, Assistant Professor, ${ }^{2}$ Dr.Vikram R, Assistant Professor, ${ }^{3}$ Dr. Rajakumar.P.G., Head of the Department, \\ Professor, ${ }^{4}$ Dr. Mohammad Ali, Associate Professor; all authors are attached with Sri Sathya Sai Medical College and \\ Research Institute, Ammapettai, Thiruporur, Chennai, India.
}

Address for Correspondence: Dr. Sowjan M, Assistant, Professor, Sri Sathya Sai Medical College and Research Institute, Ammapettai, Thiruporur, Chennai. Email: Sowjan86@gmail.com

\begin{abstract}
Dyke-Davidoff-Masson Syndrome (DDMS) is a rare disease in Indian subcontinent. It is more common in western countries. DDMS is characterized by seizures, facial asymmetry, contralateral hemiplegia and mental retardation. Characteristic radiological features are cerebral hemiatrophy with homolateral hypertrophy of skull and sinuses. We report a case of DDMS in a 9 year old girl who presented with seizures, Developmental delay in motor and speech domains, spastic hemiparesis of left upper and lower limb and MRI revealed characteristic features diagnostic of DDMS.
\end{abstract}

Keywords: Seizures, Hemiplegia, Hemiatrophy, Mental Retardation.

\section{Introduction}

Dyke-Davidoff-Masson syndrome (DDMS) is defined as the atrophy or hypoplasia of one cerebral hemisphere (hemiatrophy) which is secondary to brain insult in foetal or early childhood period [1]. More commonly they present with recurrent seizures, facial asymmetry, contralateral hemiplegia, mental retardation, or learning disabilities and speech and language disorders. Sensory loss and psychiatric manifestations like schizophrenia had been reported [2] [3]. DDMS was first described in 1933 by Dyke, Davidoff and Masson, were they described the plain skull radiographic and pneumatoencephalographic changes in a series of 9 patients with hemiplegia who had cranial asymmetry [4]. Since then not many paediatric cases has been reported in literature. We present here a 9 year old girl with typical clinical and imaging features of DDMS.

\section{Case Report}

A 9 year old girl child presented to the emergency department with H/o focal seizures involving the left arm and leg with upward rolling of eyeballs, loss of consciousness and frothing. She had seizures since third day of birth and was seizure free up to one year of age and started getting seizures after that. She was treated with phenytoin sodium and discontinued treatment for the past one year. She had increased frequency of seizures since discontinuation of treatment. Antenatal and perinatal period was uneventful. Family history was not contributory. Child had a developmental delay in motor and speech domains.

On physical examination the child was malnourished. Has microcephaly (HC-42.5cms). She had a left spastic hemiparesis, brisk tendon reflexes, decreased power with extensor plantar response and right hand preference. But there was no facial asymmetry. She has Hemiplegic gait. She was able to walk by herself. She had no neurocutaneous markers. Cranial nerve examination was normal. Blood and C.S.F studies were normal. M.R.I brain report revealed atrophy of right cerebral hemisphere with dilatation of the ipsilateral ventricle with periventricular leukomalacia on the same side. There was also shift of midline to right and thickening of calvarium on the right side. She restarted on phenytoin sodium $(5 \mathrm{mg} / \mathrm{kg})$. She had no seizures after initiation of treatment. She started receiving physiotherapy and speech therapy after admission. But there was no significant improvement in spasticity.

Manuscript received: $2^{\text {nd }}$ August 2016

Reviewed: $12^{\text {th }}$ August 2016

Author Corrected; $25^{\text {th }}$ August 2016

Accepted for Publication: $10^{\text {th }}$ September 2016 


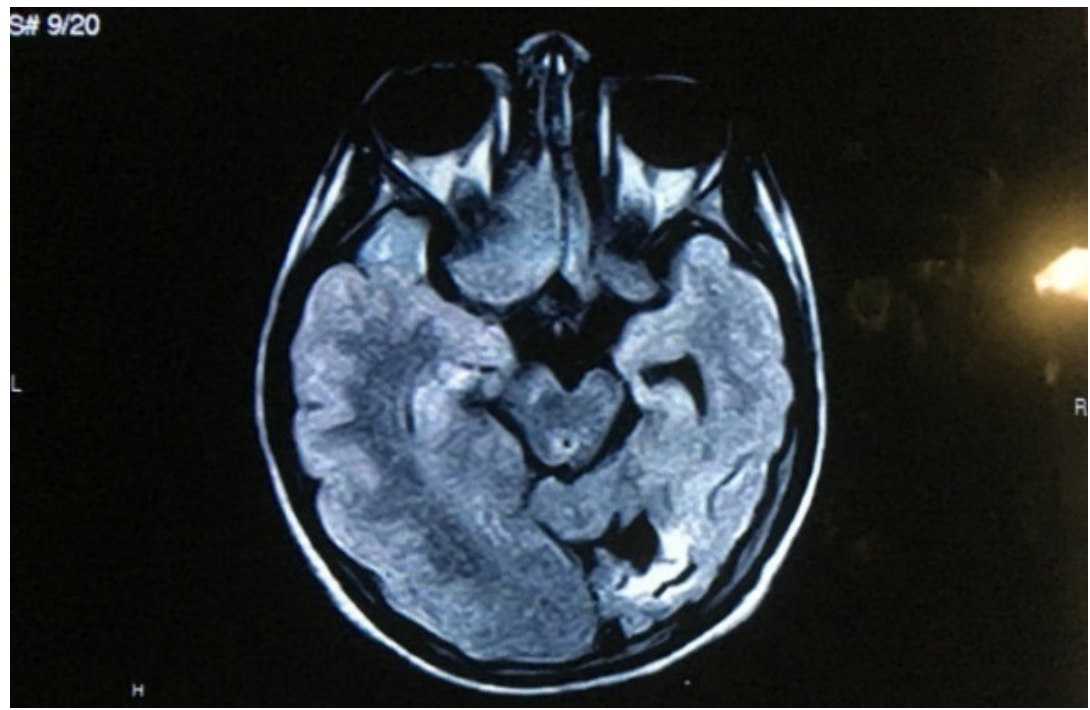

Fig-1: Hemiatrophy on the right side with midline shift to the right with periventricular leukomalacia on the same side

\section{Discussion}

DDMS is characterized by variable degree of unilateral loss of cerebral volume, contralateral hemiplegia and compensatory changes in the calvarium. The aetiology of DDMS may be roughly divided into two categories either congenital or acquired. In congenital type insult occurs in intrauterine life when maturation of calvarium has not been completed [5].

The cerebral insult is believed to be vascular in origin [6]. In acquired type, trauma, infection, vascular abnormalities, or intracranial haemorrhage may be responsible for the condition [2] [6] [7] [8]. The mechanism of cerebral atrophy is unclear, but it is hypothesised that ischemic episode from a variety of different causes reduce the production of brain derived neurotropic factors, which in turn lead to cerebral atrophy [2].

When hemiatrophy of one cerebral hemisphere appears early in life (during first two years of life) certain changes like homolateral hypertrophy of the skull and sinuses occur. The compensatory cranial changes occur to take up the relative vacuum created by the hypoplastic cerebrum. The classical clinical features of DDMS are seizures, facial asymmetry, contralateral hemiplegia or hemiparesis and mental retardation. However mental retardation was not always present and seizures may appear months or years after the onset of hemiparesis [7].

Dyke Davidoff Masson syndrome should be differentiated from Rasmussen encephalitis, silver russel syndrome, hemi convulsion-hemiplegia-epilepsy (HHE), Hemimegalencephaly, fishman syndrome, linear nevus syndrome, struge weber syndrome and Basal cell germinoma [9]. A proper clinical history and $\mathrm{CT} / \mathrm{MRI}$ findings provide the correct diagnosis.

The treatment guidelines have not been clearly developed yet because of limited experience. Treatment is symptomatic, and should target convulsion, hemiparesis and learning difficulties.

Prognosis is better if hemiparesis occurs after the age of two years and in absence of prolonged or recurrent seizures. Children with intractable disability and hemiplegia are potential candidate for hemispherectomy with successes rate of $85 \%$ in carefully selected cases [10].

Funding: Nil, Conflict of interest: Nil

Permission from IRB: Yes

\section{References}

1. Sharma S, Goyal 1, Negi A, Sood RG, Jhobta A, Surya M. Dyke-Davidoff-Masson Syndrome. Ind J Radiol Imag. 2006;16:165-166.

2. Ono K, Komai K, Ikeda T. Dyke Davidoff-Masson Syndrome manifested by seizure in late childhood: A case report. J Clin Neurosci. 2003;10:367-71.

3. Amann B, Garcia de la Iglesia C, Mckenna P, Pomarol-Clotet E, Sanchez-Guerra M, Orth M. 
Treatment- refractory Schizoaffective disorder in a patient with Dyke-Davidoff Masson Syndrome. CNS Spectr. 2009;14(1):36-39

4. Dyke CG, Davidoff LM, Masson CB. Cerebral hemiatrophy with homolateral hypertrophy of the skull and sinus. Surg Gynecol Obstet. 1933; 57: 588-600.

5. Solomon GE, Hilak SK, Gold AP, Carter S. Natural history of acute hemiplegia of childhood. Brain. 1970; 93(1) : 107-120.

6. Sener RN, Jinkins JR,MR of craniocerebral hemiatrophy. Clin Imaging. 1992Apr-Jun;16(2):93-7.

7. Zilkha A. CT of cerebral hemiatrophy. AJR Am J Roentgenol. 1980 Aug;135(2):259-62.
8. Aquiar PH, Liu CW, Leitao H, Issa F, Lepski G, Figueiredo EG, et al. MR and CT imaging in DykeDavidoff-Masson syndrome. Report of three cases and contribution to pathogenesis and differential diagnosis. Arq Neuropsiquiatr 1998 Dec;56(4):803-7

9. Rao KCVG. Degenerative diseases and hydrocephalus. In: Lee SH, Rao KDVG, Zimmerman RA, editors. Cranial MRI and CT. Fourth edition. New York: Mc Graw - Hill; 1999.p.212 - 214.

10. Narain NP, Kumar R,Narain P. Dyke-DavidoffMasson syndrome. Indian Pediatr. 2008 Nov;45 (11):927.

\section{How to cite this article?}

Sowjan M, Vikram R, Rajakumar P.G, Mohammad Ali. Dyke-Davidoff-Masson syndrome: A case report from South India. Int J Pediatr Res.2016;3(9):646-648.doi:10.17511/ijpr.2016.i09.02. 